\section{P-18 NEUROLOGICAL CARER WELL BEING PROGRAMME: A NEW INITIATIVE TO SUPPORT CARERS OF PEOPLE LIVING WITH PALLIATIVE NEUROLOGICAL CONDITIONS}

Kimberley Hunt, Julie Fletcher, Yvonne Cochrane. Teesside Hospice Care Foundation, Middlesbrough, UK

\subsection{6/bmjspcare-2016-001245.42}

Background The day hospice has observed a growing demand for services in relation to patients suffering neurological conditions, in particular the need to support their carers. Caring for someone with a progressive neurological condition can have a significant impact on their life both psychologically, emotionally and practically and a hospice setting is an ideal place to provide this support.

Aims

- To provide a specific carers well-being programme for carers of people with a palliative neurological condition.

- The aim of the programme is to develop carers' resilience through learning more about living with someone with this condition, enhancing their coping strategies and developing new ones, learning new practical skills, sharing experiences and gaining support from others in similar circumstances.

- To increase partnership working with MND specialist nurse and Parkinson's disease specialist nurse.

Method The hospice has gained funding from the Board of Trustees to extend the number of carers' groups.

In view of this, we have liaised with specialist nurses representing patients with Motor neurone disease and Parkinson's disease to discuss offering carer support.

A planning meeting is in the process of being established involving multi-disciplinary professionals from the hospice and specialist nurses to discuss and plan the well-being programme carers.

A pilot group is planned to start in July 2016.

Results The Pilot will be evaluated through a carer questionnaire and feedback from the specialist teams.

The results will be collated and presented to the Audit Group for approval of an agreed action plan.

If this pilot is successful, the group may be offered twice yearly.

Conclusion Living with a neurological condition can have a major effect both emotionally and psychologically on carers. This programme is an excellent opportunity to ensure they are supported both emotionally and psychologically improving quality of life for both carers and their loved ones.

\section{P-19 CARERS CUPPA - A SUCCESS STORY}

Sarah Green. ellenor, Gravesend, UK

\subsection{6/bmjspcare-2016-001245.43}

Background In our locality, a carers' course was undertaken by an agency for years to support them to care effectively. Topics covered were; practicalities of caring; financial support; looking after yourself; the ongoing journey; and nutrition. Our hospice was approached by the care agency to work in partnership offering the same course.

Aims

- To support more carers of patients with a life-limiting illness or disability
- Provide opportunities for carers to meet socially and support each other facilitated by volunteers

- To work in partnership with external agencies, to reach out to diverse and hard-to-reach groups

- To reach carers, pre- and post- bereavement to enhance continuity of care for carers.

Approach Informal weekly carers meetings (Carers Cuppa) were established at different times and places indicated by previous evaluations. Sessions ran for two hours with volunteers and the care agency co-facilitating. Feedback was obtained from the attendees.

Outcomes Some carers developed friendship extending out of the group setting. Carers supported one another, sharing information, ideas, problems and other supportive services. There was opportunity to speak to nursing staff and somewhere private to go if things got too much. Over the year, numbers attended increased to over 200 .

We also noticed a need for a group for bereaved carers, due to the number of carers experiencing the death of their cared-for person. Providing a Bereavement Cuppa allowed for smooth transition from the Carers Cuppa to the bereavement group.

Conclusion The feedback has been highly positive, identifying what the group means to carers. By utilising volunteers we have provided support at a small financial cost, but with huge benefit to carers. Due to the increased demand, we have further plans to increase the number of sessions

\section{P-20 DEVELOPMENT OF A HOSPICE CARERS' STRATEGY}

Rebecca Trower, Liz Reed. Princess Alice Hospice, Esher, UK

\subsection{6/bmjspcare-2016-001245.44}

Background Approximately 500,000 carers support relatives and loved ones at the end of life. Around 90\% of those with incurable illness spend the majority of the last year of life at home, often with limited support; the prevalence of anxiety and burden for carers increases in the last year of life (Ramirez et al., 1998).

Aims and objectives To raise the profile of carers' needs; to develop effective carer/staff partnerships; to respect carer experience and expertise; to enable and support carers to remain carers for as long as they wish; to develop services independently and with local partners; to develop a strategy based on service user and staff experience to take forward in meeting the needs of carers in the future.

Design Formation of a hospice steering group; workshops with current and bereaved carers; workshops with clinical and nonclinical hospice staff; thematic coding analysis; presentation and consultation of findings with participants. Development of task and finish groups to take forward recommendations made.

Findings key themes identified include the external image of hospices as places to die; variable knowledge of hospice services in the acute sector, particularly amongst medical staff; transition challenges from cure to palliation; carers' needs not always acknowledged; the physical and emotional impact of being a carer; the end of life heralds a challenging phase for carers.

Conclusion Carer needs in end-of-life care are not formally assessed and carers can experience physical and emotional problems without intervention. We are working to raise awareness of the hospice role and services available, which include local publicity campaigns, carer assessments and a number of carer-tailored support strategies including practical sessions and advice on emotional and physical wellbeing for carers, and the introduction of a 
volunteer 'carer companion' role to support carers both before and during bereavement.

\section{P-21 EVALUATING THE USE OF THE CARERS SUPPORT NEEDS ASSESSMENT TOOL (CSNAT): A PILOT STUDY}

Briony Townshend, Sandra Lawless. St Francis Hospice, Romford, UK

\subsection{6/bmjspcare-2016-001245.45}

Aim and objective To assess feasibility, acceptability and benefits of using the Carers Support Needs Assessment Tool (CSNAT) in a Day Therapy Unit (DTU) in a hospice setting.

Background The CSNAT is an evidence-based copyright tool designed by Dr G. Ewing and Prof. G. Grande which was introduced to the social work team on a study day organised by Hospice UK. It is designed to assess carers' needs in supporting a family member/friend at home towards the end-of-life. It uses a person-centred approach; providing carers with the opportunity to take control in considering, expressing and prioritising need ultimately enabling the development of a shared action plan to support carers. It was identified that this tool dovetailed well with the current practice in undertaking an assessment in the DTU whilst giving the opportunity to undertake a more holistic assessment.

Method A six-month pilot commenced September 2015 in the DTU. A total of 36 carers were assessed using the CSNAT, adhering to the 14 support domains. There was representation of carers across Barking and Dagenham (B\&D), Havering, Brentwood and Redbridge boroughs.

Results Overview of the findings showed 100\% of B\&D carers, $88 \%$ of Havering carers, $86 \%$ of Brentwood carers and $63 \%$ of Redbridge carers had needs. Concerns from carers were raised regarding illness progression, future symptoms and where to seek help if circumstances changed. Carers were able to prioritise need and demonstrate how they were managing them.

Conclusion This pilot study showed that the CSNAT is feasible and acceptable by carers with identified benefits, including carers knew they had been assessed; it promoted carers' autonomy and choice and enabled the development of action plans to provide support and timely signposting.

Implication CSNAT is being used routinely in the DTU and consideration will be made to use it within the inpatient unit and community services.

\section{Communities}

\section{P-22 DEVELOPING AND IMPLEMENTING A COMMUNITY- BASED PROSTATE CANCER AWARENESS CAMPAIGN FOR HARD-TO-REACH MEN}

Roger Wheelwright. John Taylor Hospice, Birmingham, UK

\subsection{6/bmjspcare-2016-001245.46}

Introduction Black men in the UK have substantially greater risk of developing prostate cancer (PCa) compared with white men (PCUK, 2013). This initiative aims to raise awareness of these risks and signpost this group of men to appropriate services that are available. We aim to explain this risk in a clear way that men can relate to and understand their risk.
Method This proactive project will build upon and develop initiatives with key members of the Black and African Caribbean (AC) community through the Benjamin's Brothers project at John Taylor Hospice, a concept set up with the local community, including religious and community leaders, carers and prostate cancer survivors, with clinical support from primary and secondary care.

Results Recruitment of 'health activists' to support and enable men and their families to live longer with $\mathrm{PCa}$ in the community closer to their homes offers many benefits, including:

- Improved access to advice and support to equip men and their families with the knowledge, understanding and support to self-manage their health

- Provide men and their families with a point of contact within the community who can signpost them to the appropriate services, act as a liaison between the multifaceted multidisciplinary team across primary and secondary care setting

- By providing support and education to the GPs who monitor these men in the community setting, to enable men to have access to advice and support

- Offer a new way of working and enhances the way information and support is disseminated through these communities.

Discussion The aim of the post is to:

- Offer advice and support to men of AC Heritage

- Enable those with PCa to lead as full a life as possible, taking the whole family context into account.

This gold standard ambition for people, designed with health economics in mind envisages a change to the PCa survivorship landscape.

\section{P-23 ORAL HISTORY PROJECT - ST RICHARD'S HOSPICE, 30 YEARS OF MEMORIES}

Tricia Cavell, Helen Griffee. St Richard's Hospice, Worcester, UK

10.1136/bmjspcare-2016-001245.47

In 2014 at the $30^{\text {th }}$ anniversary celebrations for St Richard's Hospice there was an overwhelming feeling from those present that the memories and experiences of those involved in the foundation of the hospice should be recorded for prosperity before it is too late. The project 'St Richard's Hospice Voices' has collected digital recordings, photos and documents charting the creation of the hospice from kitchen table to the present building and services offered to date. The project has been funded by the Heritage Lottery (HLF) as it is considered this project is 'of immeasurable heritage value' and the HLF were pleased to support the capturing of evidence for 'moments in history when palliative care changed dramatically with the emergence of the hospice movement in the UK'. Lord Howard supported the application stating 'the hospice movement has grown significantly over a 50 year period and we are fortunate to have many of their original founders still available, however, this scenario is a changing one and it is becoming increasingly important to capture their memories and thoughts as a record for in perpetuity'.

The full interview recordings are to be archived at the Worcestershire Record Office at the Hive (part of the national archive) providing researchers of the future a snapshot of the changing face of palliative care between 1984 and 2015. All the recordings and photographs are on the hospice website. 